\title{
Entropy and heat capacity of europium(III) bromide from 5 to $340 \mathrm{~K}^{\text {* }}$
}

\author{
THOMAS A. DELINE, EDGAR F. WESTRUM, JR., ${ }^{\circ}$ and \\ JOHN M. HASCHKE
}

Department of Chemistry, The University of Michigan, Ann Arbor, Michigan 48104, U.S.A.

(Received 13 September 1974; in revised form 16 January 1975)

\begin{abstract}
The heat capacity of a polycrystalline sample of $\mathrm{EuBr}_{3}$ has been measured from 5 to $340 \mathrm{~K}$ and found to be without transitions in this region. Values of the thermodynamic functions $C_{\mathrm{p}}(T),\left\{S^{\circ}(T)-S^{\circ}(5 \mathrm{~K})\right\}$, and $\left\{H^{\circ}(T)-H^{\circ}(5 \mathrm{~K})\right\} / T$ are 26.44, 43.70, and $19.66 \mathrm{cal}_{\mathrm{th}} \mathrm{K}^{-1} \mathrm{~mol}^{-1}$ respectively at $298.15 \mathrm{~K}$. A value of $S^{\circ}(298.15 \mathrm{~K})=41.42 \mathrm{cal}$ th $\mathrm{K}^{-1} \mathrm{~mol}^{-1}$, for $\mathrm{EuBr}_{3}$ from which the Schottky contribution has been deleted, is compared with an estimate of the lattice heat capacity by an empirical method.
\end{abstract}

\section{Introduction}

Enhanced interest in research on atomic energy levels of the lanthanide compounds has been evident recently. ${ }^{(1-3)}$ Thermodynamics also provides increasingly precise and reliable data on the energetic behavior of transition ${ }^{(4)}$ and lanthanide compounds ${ }^{(5)}$ and supplements the earlier data. However, empirical evaluations are still the only values extant for many important binary compounds. ${ }^{(6,7)}$ Hope that a measured value of the entropy of $\mathrm{EuBr}_{3}$ would resolve the discrepancy existing in the correlation of second- and third-law entropies for $\mathrm{EuBr}_{3}{ }^{\left({ }^{8}\right)}$ provided a major motivation for this study of the low-temperature heat capacity of $\mathrm{EuBr}_{3} . \mathrm{A}$ further dividend arises from the utility of the results in estimating values for other lanthanide trihalides.

\section{Experimental}

\section{PREPARATION AND CHARACTERIZATION OF $\mathrm{EuBr}_{3}$}

A $60 \mathrm{~g}$ sample of europium tribromide was prepared from the sesquioxide (99.99 moles per cent purity, American Potash Chemical Corp., Code 1014) by bromination of the dibromide. The previously described ${ }^{(9,10)}$ ammonium-bromide-matrix procedure was scaled for the preparation of larger $\mathrm{EuBr}_{2}$ samples. Employed in this procedure were 48.1 mass per cent aqueous $\mathrm{HBr}$ (J. T. Baker Chemical Company, containing 0.03 mass per cent $\mathrm{Cl}^{-}$as the major contaminant) and analytical grade $\mathrm{NH}_{4} \mathrm{Br}$ (Mallinckrodt Chemical Works). The dibromide was treated with analytical

- This work was supported in part by the National Science Foundation.

- To whom correspondence should be directed. 
grade $\mathrm{Br}_{2}$ (Mallinckrodt Chemical Works) in a sealed Pyrex vessel at $600 \mathrm{~K}$ and $150 \mathrm{kPa}$, a pressure which is approximately ten times the equilibrium value for the dibromide $=$ tribromide equilibrium. ${ }^{(8)}$ The pressure was controlled with a bromine reservoir which extended beyond the $600 \mathrm{~K}$ sample zone and was maintained at a minimum of $355 \mathrm{~K}$. The product was subjected to both chemical and crystallographic analyses. The europium tribromide sample was a dark rust-brown polycrystalline solid. The bromine content was determined by a gravimetric silver halide procedure, and the europium analysis was obtained by direct ignition of samples to the sesquioxide. The elemental analysis indicated $(38.78 \pm 0.05)$ mass per cent $\mathrm{Eu}$ and (61.22 \pm 0.01 ) mass per cent $\mathrm{Br}$ (theoretical: $\mathrm{Eu}, 38.80 ; \mathrm{Br}, 61.20$ ), or $\mathrm{EuBr}_{3.002 \pm 0.004}$. Powder X-ray diffraction results obtained with a $114.6 \mathrm{~mm}$ Hägg-type Guinier camera $\left(\mathrm{Cu} \mathrm{K} \alpha_{1}\right.$ radiation, $\left.\lambda=0.154051 \mathrm{~nm}\right)$ with silicon $(a=0.543062 \mathrm{~nm})$ as an internal standard showed only the presence of the orthorhombic $\mathrm{PuBr}_{3}$ structure with lattice parameters: $a=(0.9108 \pm 0.0009) \mathrm{nm}, b=(1.270 \pm 0.001) \mathrm{nm}$, and $c=(0.4010 \pm 0.0005) \mathrm{nm}$. All manipulations of the anhydrous bromides were conducted in an inert-atmosphere glove box purged of both water and oxygen.

\section{CRYOGENIC APPARATUS}

Heat-capacity measurements were made in the Mark III adiabatic cryostat which is similar in design to one previously described. ${ }^{(11)} \mathrm{A}$ gold-plated copper calorimeter (laboratory designation W-42) of about $93 \mathrm{~cm}^{3}$ volume and $41.9 \mathrm{~g}$ mass was employed for measurements on the sample. Temperatures determined with a capsule-type platinum resistance thermometer (laboratory designation A-3) are considered to be thermodynamic temperatures to within $0.03 \mathrm{~K}$ from 10 to $90 \mathrm{~K}$ and to within $0.04 \mathrm{~K}$ from 90 to $340 \mathrm{~K}$. The heat capacity of the empty calorimeter was determined separately and appropriate small adjustments were made for the slight differences in the quantities of helium and Apiezon-T grease applied between determinations. The heat capacity of the $59.8352 \mathrm{~g}$ sample varied from about 78 per cent of the total at $15 \mathrm{~K}$ to about 64 per cent at $300 \mathrm{~K}$. Helium gas $(5.60 \mathrm{kPa})$ was used to enhance the thermal equilibrium between sample and calorimeter. All determinations of mass, potential, current, and temperature were referred to calibrations performed by the National Bureau of Standards.

\section{Results and discussion}

The experimentally determined heat capacities for $\mathrm{EuBr}_{3}$ are presented in table 1 . The temperatures given in the table represent the mean temperatures for the temperature increments employed in the individual runs and are considered to have a probable error ranging from 3 per cent at $5 \mathrm{~K}$ to 0.5 per cent at $10 \mathrm{~K}$ to less than 0.1 per cent above $20 \mathrm{~K}$. The results are based on a molar mass of $391.67 \mathrm{~g} \mathrm{~mol}^{-1}$ for $\mathrm{EuBr}_{3}$ (1968 atomic weights). All temperatures are on the IPTS-48.

The smoothed heat capacities and thermodynamic functions at selected temperatures are presented in table 2 . The heat-capacity values were taken from a smooth curve obtained by a digital computer least-squares fitted polynomial function through the experimental points. The values below $12 \mathrm{~K}$ are the result of extrapolation using 
TABLE 1. Heat capacity of europium tribromide

$\left(\mathrm{cal}_{\mathrm{th}}=4.184 \mathrm{~J}\right)$

\begin{tabular}{|c|c|c|c|c|c|c|c|}
\hline$\frac{T}{\mathbf{K}}$ & $\frac{C_{\mathrm{p}}}{\mathrm{cal}_{\mathrm{th}} \mathrm{K}^{-1} \mathrm{~mol}^{-1}}$ & $\frac{T}{\mathrm{~K}}$ & $\frac{C_{p}}{\mathrm{cal}_{\mathfrak{t n}} \mathrm{K}^{-1} \mathrm{~mol}^{-1}}$ & $\frac{T}{\mathbf{K}}$ & $\frac{C_{\mathrm{p}}}{\mathrm{cal}_{\mathrm{th}} \mathrm{K}^{-1} \mathrm{~mol}^{-1}}$ & $\frac{T}{\mathbf{K}}$ & $\frac{C_{\mathrm{p}}}{\mathrm{cal}_{\mathrm{th}} \mathrm{K}^{-1} \mathrm{~mol}^{-1}}$ \\
\hline & Series I & 20.55 & 0.500 & 62.91 & 3.894 & 169.88 & 7.676 \\
\hline 5.18 & 0.015 & 22.56 & 0.618 & 68.04 & 4.254 & 179.94 & 7.797 \\
\hline 5.77 & 0.018 & 24.56 & 0.747 & 72.77 & 4.558 & 189.87 & 7.902 \\
\hline 6.43 & 0.024 & 26.52 & 0.884 & 77.21 & 4.830 & 199.67 & 7.995 \\
\hline 7.15 & 0.032 & 28.82 & 1.054 & 82.05 & 5.113 & 209.36 & 8.080 \\
\hline 7.80 & 0.046 & 31.63 & 1.277 & 88.69 & 5.473 & 219.42 & 8.164 \\
\hline 8.53 & 0.063 & 34.71 & 1.537 & & & 229.84 & 8.241 \\
\hline 9.27 & 0.082 & 37.51 & 1.780 & \multirow{2}{*}{\multicolumn{2}{|c|}{ Series III }} & 240.60 & 8.315 \\
\hline 9.98 & 0.104 & 40.54 & 2.044 & & & 251.70 & 8.381 \\
\hline 10.79 & 0.113 & 43.62 & 2.314 & 88.46 & 5.456 & 262.72 & 8.445 \\
\hline 11.74 & 0.135 & 46.70 & 2.585 & 98.16 & 5.878 & 273.66 & 8.500 \\
\hline 12.72 & 0.163 & 50.86 & 2.941 & 107.28 & 6.228 & 283.54 & 8.547 \\
\hline 13.69 & 0.195 & 55.56 & 3.326 & 116.67 & 6.550 & 295.35 & 8.595 \\
\hline 14.82 & 0.233 & 60.09 & 3.683 & 127.34 & 6.853 & 306.11 & 8.639 \\
\hline 16.15 & 0.286 & \multirow{2}{*}{\multicolumn{2}{|c|}{ Series II }} & 138.45 & 7.135 & 316.82 & 8.681 \\
\hline 17.46 & 0.343 & & & 149.18 & 7.350 & 327.48 & 8.719 \\
\hline 18.83 & 0.409 & 58.01 & 3.517 & 159.64 & 7.522 & 338.08 & 8.760 \\
\hline
\end{tabular}

the Debye limiting law. The estimated error in the thermodynamic functions is less than 0.1 per cent above $100 \mathrm{~K}$.

The quantum number $J$ resulting from spin-orbit (Russell-Saunders) coupling prevails with $4 \mathrm{f}$ elements. $\mathrm{Eu}^{3+}$ (or Eu IV in spectroscopic notation) has a ground term of ${ }^{7} F_{0}$ which is diamagnetic. However, the other terms of the ground multiplet $\left({ }^{7} F_{1,2,3,4,5,6}\right)$ contribute to the thermodynamic properties of trivalent europium significantly at $298.15 \mathrm{~K}$. In fact, estimates show that the scparation between the $J=0$ ground state and the $J=1$ first excited state is about (5/3)kT at room temperature. Hence, Schottky contributions to the heat capacity are to be expected in $\mathrm{EuBr}_{3}$ even below $340 \mathrm{~K}$, but Boltzmann statistics show that Schottky contributions to the heat capacity below $5 \mathrm{~K}$ are negligible. Absence of discontinuities in the heat capacity from 5 to $340 \mathrm{~K}$ is conclusive evidence for the lack of cooperative phenomena in this temperature range. Nuclear magnetic contributions to the heat capacity from below $5 \mathrm{~K}$ are possible.

Haschke has noted the dark brown color of $\mathrm{EuBr}_{3}$ (in contrast with the colorless nature of other europium(III) compounds) and that the color in $\mathrm{EuBr}_{3}$ tends to fade at low temperatures. ${ }^{(8)}$ He speculates that the color might be due to the excitation of electrons into low-lying energy levels of the $\mathrm{Eu}^{3+}$ ion. Consideration of the wavenumber of the light absorbed (about $20000 \mathrm{~cm}^{-1}$ ), however, shows that energy levels would have to involve $D$ states with wavenumbers lying about $18000 \mathrm{~cm}^{-1}$ above the ground state. This speculation is supported by the data of McClure. ${ }^{(12)}$ The results suggest that the alternative possibility, ${ }^{(8)}$ a bromide to europium(III) charge transfer, is the probable origin of the visible absorption.

In the absence of data on the crystal field levels on $\mathrm{EuBr}_{3}$, we have selected spectroscopic data for the $\mathrm{Eu}$ IV levels in $\mathrm{EuYVO}_{4}{ }^{(1)}$ as an approximation to free ion levels. 
TABLE 2. Thermodynamic functions for europium tribromide

$$
\left(\mathrm{cal}_{\mathrm{th}}=4.184 \mathrm{~J}\right)
$$

\begin{tabular}{|c|c|c|c|c|}
\hline$\frac{T}{\mathrm{~K}}$ & $\frac{C_{p}}{\mathrm{cal}_{\mathrm{th}} \mathrm{K}^{-1} \mathrm{~mol}^{-1}}$ & $\frac{\left\{S^{\circ}(T)-S^{\circ}(0)\right\}}{\mathrm{cal}_{\mathrm{th}} \mathrm{K}^{-1} \mathrm{~mol}^{-1}}$ & $\frac{\left\{H^{\circ}(T)-H^{\circ}(0)\right\}}{\mathrm{cal}_{\mathrm{th}} \mathrm{K}^{-1} \mathrm{~mol}^{-1}}$ & $\frac{-\left\{G^{\circ}(T)-H^{\circ}(0)\right\} / T}{\mathrm{cal}_{\mathrm{th}} \mathrm{K}^{-1} \mathrm{~mol}^{-1}}$ \\
\hline 5 & 0.06 & 0.019 & 0.07 & 0.005 \\
\hline 10 & 0.44 & 0.148 & 1.18 & 0.03 \\
\hline 15 & 1.266 & 0.486 & 5.39 & 0.127 \\
\hline 20 & 2.373 & 0.995 & 14.36 & 0.277 \\
\hline 25 & 3.739 & 1.667 & 29.56 & 0.485 \\
\hline 30 & 5.256 & 2.481 & 52.00 & 0.748 \\
\hline 35 & 6.822 & 3.409 & 82.20 & 1.061 \\
\hline 40 & 8.361 & 4.421 & 120.18 & 1.417 \\
\hline 45 & 9.826 & 5.492 & 165.68 & 1.810 \\
\hline 50 & 11.180 & 6.598 & 218.25 & 2.233 \\
\hline 60 & 13.580 & 8.857 & 342.48 & 3.149 \\
\hline 70 & 15.60 & 11.11 & 488.7 & 4.125 \\
\hline 80 & 17.29 & 13.30 & 653.4 & 5.136 \\
\hline 90 & 18.72 & 15.42 & 833.6 & 6.162 \\
\hline 100 & 19.92 & 17.46 & 1027.0 & 7.191 \\
\hline 110 & 20.93 & 19.41 & 1231.4 & 8.213 \\
\hline 120 & 21.77 & 21.27 & 1445.0 & 9.224 \\
\hline 130 & 22.48 & 23.04 & 1666.4 & 10.219 \\
\hline 140 & 23.08 & 24.73 & 1894.3 & 11.196 \\
\hline 150 & 23.59 & 26.34 & 2127.7 & 12.152 \\
\hline 160 & 24.02 & 27.87 & 2365.8 & 13.087 \\
\hline 170 & 24.38 & 29.34 & 2607.9 & 14.000 \\
\hline 180 & 24.69 & 30.74 & 2853.3 & 14.891 \\
\hline 190 & 24.96 & 32.09 & 3101.6 & 15.761 \\
\hline 200 & 25.19 & 33.37 & 3352.4 & 16.610 \\
\hline 210 & 25.39 & 34.61 & 3605.3 & 17.438 \\
\hline 220 & 25.56 & 35.79 & 3860.0 & 18.245 \\
\hline 230 & 25.71 & 36.93 & 4116.4 & 19.033 \\
\hline 240 & 25.85 & 38.03 & 4374.2 & 19.802 \\
\hline 250 & 25.97 & 39.09 & 4633.3 & 20.552 \\
\hline 260 & 26.08 & 40.11 & 4893.6 & 21.285 \\
\hline 270 & 26.18 & 41.09 & 5155 & 22.000 \\
\hline 280 & 26.27 & 42.05 & 5417 & 22.700 \\
\hline 290 & 26.37 & 42.97 & 5680 & 23.382 \\
\hline 300 & 26.46 & 43.86 & 5944 & 24.050 \\
\hline 310 & 26.54 & 44.73 & 6209 & 24.703 \\
\hline 320 & 26.63 & 45.58 & 6475 & 25.343 \\
\hline 330 & 26.72 & 46.40 & 6742 & 25.968 \\
\hline 340 & 26.80 & 47.20 & 7010 & 26.581 \\
\hline 273.15 & 25.21 & 41.40 & 5237 & 22.222 \\
\hline 298.15 & 26.44 & 43.70 & 5896 & 23.928 \\
\hline
\end{tabular}

The Schottky contribution evaluated from these: $\left(T / \mathrm{K}, C_{p, 1} / \mathrm{cal}_{\mathrm{th}} \mathrm{K}^{-1} \mathrm{~mol}^{-1}\right.$, $S_{\mathrm{i}} / \mathrm{cal}_{\text {th }} \mathrm{K}^{-1} \mathrm{~mol}^{-1}$ ): 50, 0.019, 0.002; 100, 0.859, 0.200;200, 2.24, 1.38; 300, 2.24, $2.30 ; 500,2.26,3.44 ; 1000,2.30,5.04$, when deducted from the observed $\left\{S^{\circ}(300 \mathrm{~K})\right.$ $\left.-S^{\circ}(5 \mathrm{~K})\right\}$ yields a lattice entropy of $41.5 \mathrm{cal}_{\mathrm{th}} \mathrm{K}^{-1} \mathrm{~mol}^{-1}$ in reasonable accord with 41.1 estimated by Latimer's ${ }^{(13)}$ scheme. 
The measured value of $S^{\circ}(298.15 \mathrm{~K})$ for $\mathrm{EuBr}_{3}\left(43.86 \mathrm{cal}_{\mathrm{th}} \mathrm{K}^{-1} \mathrm{~mol}^{-1}\right)$ is signifcantly lower than the estimated value $\left(48 \mathrm{cal}_{\mathrm{th}} \mathrm{K}^{-1} \mathrm{~mol}^{-1}\right.$ ) employed in the third-law calculation for the vaporization of the tribromide. ${ }^{(8)}$ In the light of these results, a reevaluation of the estimates for $\mathrm{EuBr}_{2}(\mathrm{~s})$ and the third-law calculations may be merited.

The authors thank Dr Bruce H. Justice for stimulating discussion on some aspects of the problem. They acknowledge the support of this research (initiated under the Division of Research of the U.S. Atomic Energy Commission) by the National Science Foundation. Acknowledgment is made to the donors of The Petroleum Research Fund, administered by the American Chemical Society for partial support of this research.

\section{REFERENCES}

1. Brecher, C.; Samelson, H.; Lempicki, A. The Energy Level Structure of $\mathrm{Eu}^{3+}$ in $\mathrm{YVO}_{4}$. In Optical Properties of Ions in Crystals, Crosswhite, H. M.; Moos, H. W.; editors. Interscience: New York. 1967.

2. Henderson, J. R.; Muramoto, M.; Henderson, T. M.; Gruber, J. B. J. Chem. Phys. 1967, 47, 5097.

3. Gruber, J. B.; Krupke, W. F.; Poindexter, J. M. J. Chem. Phys. 1964, 41, 3363. Kisliuk, P.; Krukpe, W. F.; Gruber, J. B. ibid, 1964, 40, 3606.

4. Haschke, J. M.; Eich, H. A. J. Phys. Chem. 1970, 74, 1806.

5. Justice, B. H.; Westrum, E. F., Jr. J. Phys. Chem. 1963, 67, 339; ibid, 67, 365; ibid, 67, 659.

6. Westrum, E. F., Jr. Developments in Chemical Thermodynamics of the Lanthanides. In Lanthanide/ Actinide Chemistry, Gould, R. F.; editor. American Chemical Society: Washington, D.C. 1967, p. 25.

7. Mills, K. C. Thermodynamic Data for Inorganic Sulphides, Selenides and Tellurides. Butterworths: London. 1974.

8. Haschke, J. M. J. Chem. Thermodynamics 1973, 5, 283.

9. Taylor, M. D.; Carter, C. P. J. Inorg. Nucl. Chem. 1962, 24, 387.

10. Haschke, J. M.; Eick, H. A. J. Inorg. Nucl. Chem. 1970, 32, 2153.

11. Westrum, E. F., Jr.; Furukawa, G. T.; McCullough, J. P. Adiabatic low-temperature calorimetry. Chap. 5 in Experimental Thermodynamics, Vol. I. McCullough, J. P.; Scott, D. W.; editors. Butterworths: London. 1968.

12. McClure, D. S. Electronic Spectra of Molecules and Ions in Crystals in Solid State Physics, Vol. 9. Seitz, F.; Turnbull, D.; editors. Academic Press: New York. 1959.

13. Latimer, W. M. J. Amer. Chem. Soc. 1921, 43. 818; ibid. 1951. 73, 1480. 